\title{
INFESTAÇÃO E DANOS DE Cinara atlantica RELACIONADOS COM O ESTADO NUTRICIONAL E HÍDRICO EM MUDAS DE Pinus taeda L.
}

\author{
Elisiane Castro de Queiroz*, Renato Dedecek**, Sonia Maria Noemberg Lazzari***, \\ Wilson Reis Filho**** \\ *Bióloga, M.Sc. - elisianequeiroz@pop.com.br \\ **Eng. Agrônomo, Ph.D., Embrapa Florestas - dedecek@cnpf.embrapa.br \\ ***Bióloga, Ph.D., Depto. de Zoologia, UFPR - lazzari@ufpr.br \\ ****Eng. Agrônomo, Dr., Epagri / Embrapa Florestas - wilson@cnpf.embrapa.br \\ Recebido para publicação: 03/05/2004 - Aceito para publicação: 12/06/2007
}

\begin{abstract}
Resumo
Foi avaliada a resposta de populações de Cinara atlantica ao estado nutricional de mudas de Pinus taeda L., em condições de campo no município de Três Barras (SC), e ao estresse hídrico, em casa de vegetação em Colombo (PR). Em casa de vegetação, foram avaliados 4 tratamentos com 30 mudas cada: plantas não-estressadas (com 60\% da capacidade de campo) e estressadas (com 30\% da capacidade de campo), ambos com e sem insetos. Cada planta foi infestada com 10 ninfas de $3^{\circ}$ e $4^{\circ}$ instar. Semanalmente, era contado o número de afídeos, medidos a altura e o diâmetro de todas as plantas e acrescentado o volume de água correspondente. Em campo, foram plantadas 60 plantas, das quais, quinzenalmente, 15 plantas eram arrancadas ao acaso, contando-se o número de afídeos por planta e analisando-se o estado nutricional, durante dois meses. Constatou-se que o aumento do teor de nitrogênio nas mudas de $P$. taeda correlaciona-se diretamente com o aumento no número de insetos. As mudas com estresse hídrico apresentaram maiores teores de nitrogênio e incidência de pulgões. Em casa de vegetação, as plantas apresentaram menor crescimento em altura na presença de insetos, com ou sem estresse hídrico. As mudas infestadas apresentaram maior crescimento em diâmetro, independentemente do estresse hídrico, no tempo observado e condições do estudo.

Palavras-chave: Estresse hídrico; nutrição de planta; pulgão-gigante-do-pinus.
\end{abstract}

\begin{abstract}
Infestation and damages of Cinara atlantica due to nutritional status and to water stress on Pinus taeda L. seedlings. The response of Cinara atlantica population to the nutritional status of recently planted seedlings of $P$. taeda was evaluated on field, in Três Barras city in the state of Santa Catarina, and to water stress in greenhouse, in Colombo city, Paraná state. In the greenhouse, 4 treatments were tested with 30 plants each treatment: non-stressed seedlings (at $60 \%$ of field capacity) and the stressed ones (at only $30 \%$ of field capacity), with and without insects. Each plant was infested with 10 nymphs of $3^{\text {rd }}$ and $4^{\text {th }}$ instars. Weekly, the number of aphids was counted, the height and diameter of the plants were measured, the nutritional status of the needles were analyzed and the volume of water applied accordingly. It was observed that the recently-planted seedlings were less attractive to $C$. atlantica because of their low $\mathrm{N}$ content condition caused by planting stress. The infestation of the water stressed plants in the greenhouse was the double of the population on the non-stressed plants. Plant height increased directly proportional to the aphid infestation and the impact of the insects was equivalent to that resulting from the water stress. The infested seedlings also presented an increasing in diameter, but there was no influence of water stress.

Keywords: Plant nutrition; water stress; giant conifer aphid.
\end{abstract}

\section{INTRODUÇ̃̃O}

O cultivo de Pinus spp (Pinaceae) representa aproximadamente 2,2 milhões de ha no Brasil, principalmente nas regiões Sul e Sudeste, e está sujeito ao ataque do pulgão-gigante-do-pinus, Cinara atlantica Wilson, 1919 (Hemiptera: Aphididae). Esses afídeos são originários dos Estados Unidos e do 
Canadá, onde se encontram amplamente distribuídos, sem, contudo se constituírem em pragas significativas nessas regiões.

Os adultos e ninfas de Cinara sugam a seiva da planta, causando dessecação do tecido e, em altas populações, provocam a seca dos ramos e a morte da árvore, especialmente das mudas. Como dano secundário, há o desenvolvimento de fumagina sobre a secreção açucarada dos afídeos, interferindo nas trocas gasosas e na fotossíntese da planta (FURNISS; CAROLIN, 1977; KFIR et al., 1985; MILLS, 1990; IEDE, 2003).

O crescimento em altura e diâmetro de mudas de Pinus taeda L. com um e dois anos sofre uma redução significativa quando elas são atacadas por Cinara spp. (FOX; GRIFFITHS, 1977). Iede (2003), comparando plantios jovens de $P$. taeda infestados por $C$. atlantica, registrou, em Rio Negrinho (SC), uma perda no diâmetro de 13,7\%, e na altura, de 17,4\%, porém em Arapoti (PR) não houve diferença significativa nesses parâmetros. Zaleski (2003), em experimentos realizados em casa de vegetação com mudas de $P$. taeda com 90 dias, infestadas artificialmente com até 50 espécimes de C. atlantica, constatou uma redução de $24,5 \%$ na altura e $7,8 \%$ no diâmetro, quando comparou os resultados com a testemunha sem infestação. Já nas mudas com 150 dias, a redução foi de $26,2 \%$.

Em relação à altura, Faria (2004), avaliando a proteção que Imidacloprid oferece em mudas de $P$. taeda à infestação de $C$. atlantica, através de experimentos em campo, no município de Três Barras (SC), verificou que, em função da infestação de $C$. atlantica, quarenta dias após o plantio, as plantas sem aplicação de Imidacloprid cresceram em altura num ritmo inferior em relação às protegidas com essa molécula.

Em função desses danos, várias ações foram adotadas para o controle desse inseto, com destaque para a melhoria do sistema de manejo de vegetação nos povoamentos, a aplicação do inseticida Imidacloprid nos viveiros e a implantação do programa de controle biológico clássico, com a introdução, no Sul do Brasil, do parasitóide Xenostigmus bifasciatus Ashmead, 1891 (Hymenoptera: Braconidae), com a participação da Embrapa Florestas, do Departamento de Zoologia da Universidade Federal do Paraná, da Funcema (Fundo Nacional de Controle à Vespa-da-madeira), da Epagri e da Universidade de Illinois. Essas ações, somadas à incorporação do pulgão na dieta do complexo de inimigos naturais nativos, têm provocado redução nas populações de $C$. atlantica.

Diante desses fatos, o estudo das interações inseto-planta, do efeito da condição nutricional da planta, bem como das relações afídeo-inimigo natural e da influência de fatores abióticos sobre as populações de Cinara, é importante para orientar práticas silviculturais adequadas que possam contribuir para o manejo integrado desses insetos. Assim, com o intento de contribuir com o entendimento desses fatores, os objetivos desta pesquisa foram: correlacionar as infestações de $C$. atlantica com o estado nutricional e a idade das mudas de $P$. taeda e avaliar a infestação e os danos de $C$. atlantica em condições de estresse hídrico, em casa de vegetação.

\section{MATERIAL E MÉTODOS}

\section{Avaliação do estado nutricional das plantas em campo}

Para avaliação do estado nutricional das plantas, foram conduzidos experimentos em campo e em casa de vegetação. Os experimentos de campo foram desenvolvidos no período de dezembro de 2004 a fevereiro de 2005, na Fazenda do Bugre, da Empresa Rigesa Westvaco, no município de Três Barras (SC), na região do Planalto Norte Catarinense, sob coordenadas geográficas de $26^{\circ} 07^{\prime} 41^{\prime}$ ' de latitude Sul e 50¹9'30" de longitude Oeste. As mudas de P. taeda foram produzidas em tubetes pela empresa e transferidas para o campo com seis meses, plantadas com espaçamento 2,5 x 2,5, dispostas em uma linha com 60 plantas.

Quinze dias após o plantio, 15 plantas foram retiradas ao acaso e colocadas em sacos plásticos para a análise nutricional. Esse procedimento repetiu-se por mais três vezes, com intervalos de 15 dias, totalizando quatro amostragens (60 plantas), durante dois meses. No laboratório, as amostras de acículas foram secadas em estufa com circulação forçada de ar, a uma temperatura de $60-65{ }^{\circ} \mathrm{C}$, até peso constante. Após a secagem, foi feita a moagem do material foliar em moinho Willey, com peneira de 20 "mesh". Em seguida, o material foi encaminhado ao Laboratório da Embrapa Florestas em Colombo (PR), para a análise foliar pelo método sugerido por Sarruge; Haag (1974). As amostras foram digeridas por via 
úmida, empregando-se a digestão nitroperclórica. Os teores de N (nitrogênio) foram determinados pelo método Semi-Micro-Kjeldahl.

Efeito da infestação de $C$. atlantica e do estresse hídrico sobre o desenvolvimento das mudas de $P$. taeda

Este experimento foi realizado em casa de vegetação na Embrapa Florestas, Colombo (PR), sob

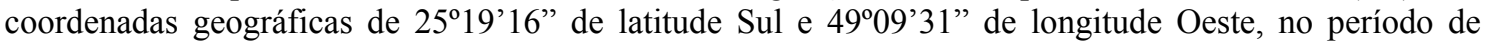
setembro de 2004 a maio de 2005, a fim de avaliar o efeito do estresse hídrico sobre as infestações de $C$. atlantica. Foram selecionadas 120 mudas de $P$. taeda da mesma progênie utilizada no experimento de campo, que foram plantadas em 28/09/2004, em garrafas plásticas transparentes, tipo pet, cortadas abaixo do gargalo, com solo proveniente de Três Barras (SC) (Latossolo Vermelho Escuro), não sendo realizada adubação. Foram testados quatro tratamentos: Tratamento $1-$ com estresse $(30 \%$ da capacidade de campo) e sem inseto; Tratamento 2 - com estresse e com inseto; Tratamento 3 - sem estresse $(60 \%$ da capacidade de campo) e sem inseto; Tratamento 4 - sem estresse e com inseto.

As plantas foram distribuídas em quatro gaiolas de voil $(1,90 \mathrm{~m}$ de altura por $0,90 \mathrm{~m}$ de largura e $1,90 \mathrm{~m}$ de comprimento), considerando-se cada planta uma repetição. Na gaiola 1 ficaram as plantas com estresse hídrico e sem inseto; na gaiola 2 as plantas estressadas e com inseto; na gaiola 3 as nãoestressadas e sem inseto e na gaiola 4 as sem estresse e com inseto. Cada muda foi infestada com 10 ninfas de $3^{\circ}$ e $4^{\circ}$ instar. A altura e o diâmetro de todas as plantas foram medidos no início e no final do experimento. Uma vez por semana, os afídeos eram contados. Ao final do experimento, foram retiradas seis plantas de cada gaiola para análise do teor de $\mathrm{N}$, com exceção da gaiola com as plantas estressadas e com inseto, da qual se usaram 12 plantas, para garantir a precisão dos dados. Foram utilizadas as plantas inteiras (acículas + caule), eliminando-se as raízes.

Para a determinação da quantidade de água nas mudas, as garrafas foram pesadas sem e com terra seca e depois com a planta. Com base na densidade do solo em cada garrafa, foi calculada a quantidade de água necessária para atingir o ponto de saturação. As plantas eram pesadas em balança de precisão, duas vezes por semana, para completar a água. Após o estabelecimento das mudas, iniciou-se o estresse hídrico. Para as 60 plantas não-estressadas, a quantidade de água foi ajustada para 671 $\mathrm{ml} /$ garrafa, ficando com o peso final de $2006 \mathrm{~g} \mathrm{(60 \%} \mathrm{da} \mathrm{capacidade} \mathrm{de} \mathrm{campo).} \mathrm{Para} \mathrm{o} \mathrm{tratamento} \mathrm{com}$

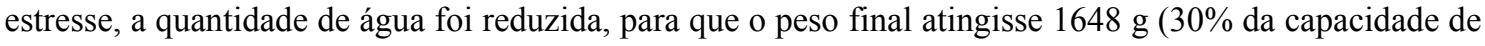
campo).

\section{RESULTADOS E DISCUSSÃO}

Infestação das mudas de $P$. taeda por $C$. atlantica em função da idade e condição nutricional das plantas

Quinze dias após o plantio, observou-se que as mudas apresentaram baixo nível de nitrogênio ( 9 $\mathrm{g} \mathrm{kg}^{-1}$ - Figura 1), provavelmente por ainda estarem utilizando os nutrientes restritos ao substrato contido no tubete. Com o decorrer dos dias de plantio, observou-se que o teor de $\mathrm{N}$ aumentou. Na tabela 1 , observa-se que com 45 dias após o plantio as mudas atingiram teores de $\mathrm{N}$ próximos de $17 \mathrm{~g} \mathrm{~kg}^{-1}$, e com 60 dias $18 \mathrm{~g} \mathrm{~kg}^{-1}$ de $\mathrm{N}$, que são teores considerados normais para $P$. taeda, segundo Reissman; Wisnewski

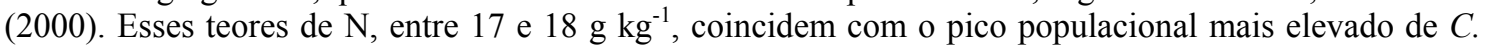
atlantica (Figura 1), indicando que à medida que o teor de nitrogênio aumentou nas mudas, elas se tornaram mais atrativas para os pulgões.

Esse aumento do teor de N, coincidindo com o pico populacional dos insetos, pode ter ocorrido pela emissão de novas raízes, que podem ter aumentado a absorção de $\mathrm{N}$ do solo. Também pode ter acontecido devido ao crescimento de brotos, pois, segundo Mittler (1958) e Dixon (1970), citados por Kidd (1985), a quantidade de $\mathrm{N}$ sofre alterações à medida que as folhas e os brotos crescem e maturam.

Outra possibilidade que pode ter favorecido o aumento do número de insetos é a estiagem constatada no período (Tabela 1), levando as plantas a um possível estresse hídrico que, segundo Wearing; Van Emden (1967), provoca uma hidrólise das proteínas e, conseqüentemente, um enriquecimento em nitrogênio solúvel, que acarreta um aumento, mesmo que temporário, das populações de afídeos. 


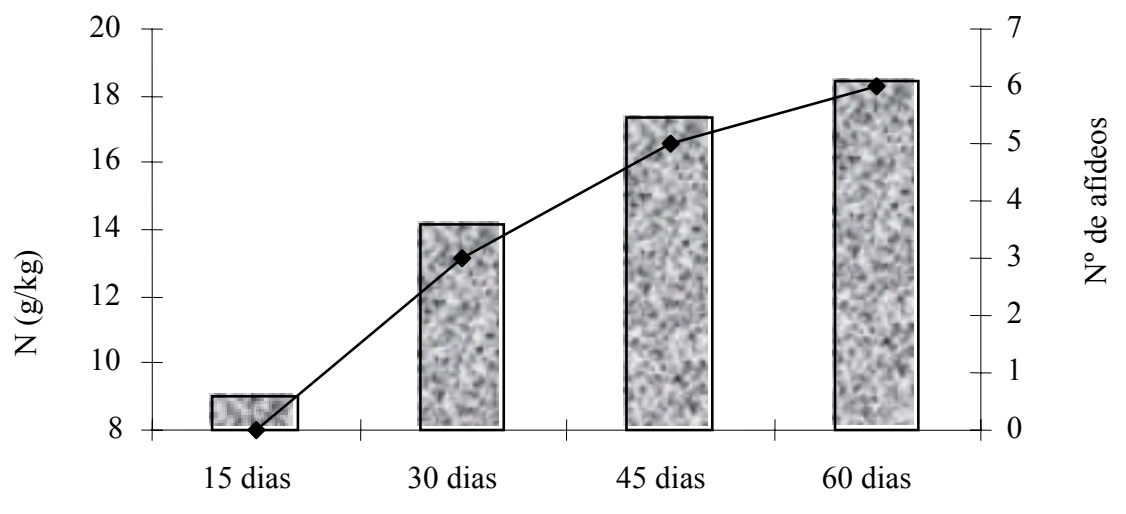

Idade do plantio

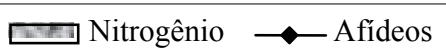

Figura 1. Número total de Cinara atlantica por planta e teor médio de nitrogênio nas acículas de 15 mudas de Pinus taeda, a partir de 15 dias após o transplante, iniciando em dezembro de 2004, Três Barras (SC).

Figure 1. Total number of Cinara atlantica by plant and average $\mathrm{N}$ content in the needles of 15 seedlings of Pinus taeda, beginning 15 days after planting, starting on December 2004, Três Barras (SC).

Tabela 1. Dados de precipitação pluviométrica $(\mathrm{mm})$ e temperatura $\left({ }^{\circ} \mathrm{C}\right)$ em campo, a partir do plantio de Pinus taeda, Três Barras (SC).

Table 1. Rainfall and temperature data, starting at planting date of Pinus taeda, Três Barras (SC).

\begin{tabular}{lcccc}
\hline Parâmetro & $\mathbf{1 5}$ dias & $\mathbf{3 0}$ dias & $\mathbf{4 5}$ dias & $\mathbf{6 0}$ dias \\
\hline Precipitação pluviométrica & 29,5 & 38,4 & 37,6 & 36,1 \\
Temperatura mínima & 15,1 & 15,2 & 17,1 & 16,0 \\
Temperatura máxima & 25,6 & 27,0 & 29,1 & 25,4 \\
Temperatura média & 20,3 & 21,1 & 23,1 & 20,7 \\
\hline
\end{tabular}

A ocorrência da estiagem citada foi determinada com base nas informações do Atlas Climatológico de Santa Catarina (Pandolfo et al., 2002), de acordo com o qual a precipitação pluviométrica normal mensal para a região de Três Barras, nos meses de dezembro, janeiro e fevereiro, é de 130 a $150 \mathrm{~mm}$. Pelos dados da tabela 1, a chuva verificada nesse período de 60 dias equivale ao esperado para apenas um mês, o que permite uma idéia da deficiência de água no período de estudo.

\section{Infestação de $C$. atlantica em mudas de $P$. taeda sob condições de estresse hídrico em casa de vegetação}

Observou-se que a infestação de $C$. atlantica foi significativamente mais elevada nas plantas submetidas ao estresse hídrico, com a média de 101,3 afídeos por planta, em relação às plantas não estressadas, com a média de 46,7 pulgões por planta (Figura 2).

Ribeiro et al. (2003), em testes com mudas de $P$. taeda plantadas em vasos com três quilos de solo e com três tratamentos com doses diferentes de água, observaram que a incidência e o desenvolvimento de $C$. atlantica foi maior onde o solo estava sempre saturado com água, demonstrando que tanto o excesso de água quanto a falta, como observamos neste trabalho, provocam o estresse para a planta, tornando-a mais atrativa para os insetos.

As temperaturas médias nas gaiolas dentro da casa de vegetação no mês de maio foram: mínima de $13,1{ }^{\circ} \mathrm{C}$, máxima de $25,2{ }^{\circ} \mathrm{C}$ e média de $19,2{ }^{\circ} \mathrm{C}$, temperaturas estas dentro de limites que não afetam notavelmente as populações de C. atlantica, pois, de acordo com Ottati (2004), as temperaturas constantes 
de $18^{\circ} \mathrm{C}$ e $22^{\circ} \mathrm{C}$ são as mais adequadas para o desenvolvimento de C. atlantica. Já para Zaleski (2003), a temperatura mais favorável para o desenvolvimento dessa espécie é $15^{\circ} \mathrm{C}$.

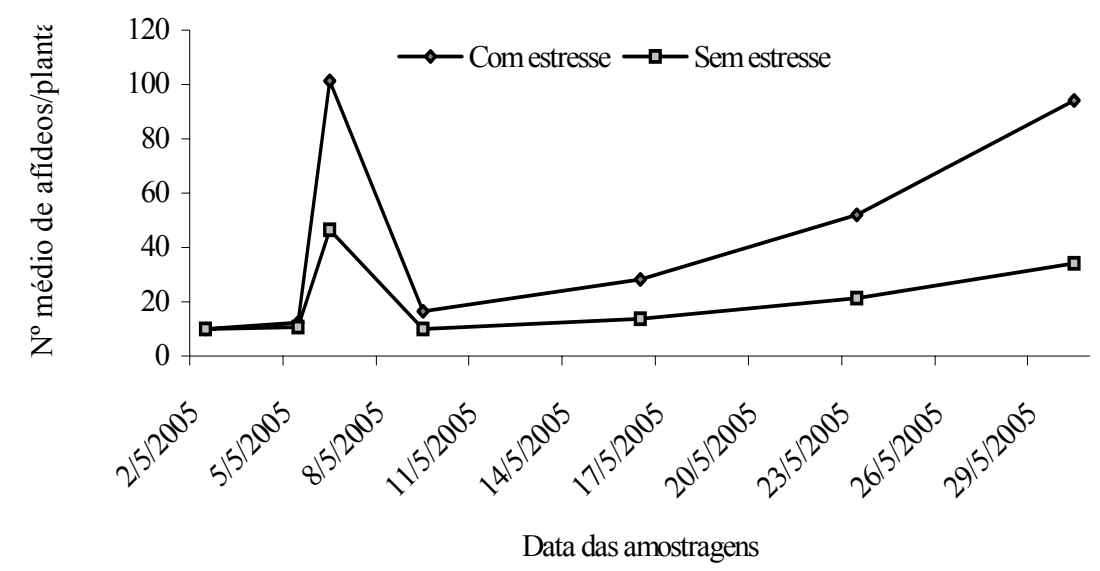

Figura 2. Número médio de espécimes de Cinara atlantica por muda de Pinus taeda, em tratamentos com e sem estresse hídrico em casa de vegetação, Colombo (PR).

Figure 2. Average number of Cinara atlantica specimens by seedling of Pinus taeda, in treatments with water stressed and non-stressed plants in greenhouse, Colombo (PR).

Os teores médios de $\mathrm{N}$ das plantas para cada tratamento são apresentados na tabela 2. Não houve diferença significativa no teor de nitrogênio nas plantas não-estressadas com e sem insetos. Contudo, as plantas estressadas não-infestadas apresentaram um teor de nitrogênio significativamente mais elevado do que aquelas que não foram submetidas ao estresse hídrico, tanto com como sem infestação (Tabela 2). Mesmo assim, observa-se que os teores de $\mathrm{N}$ nas plantas infestadas foram inferiores aos das plantas nãoinfestadas, sendo essa diferença mais acentuada nas plantas com estresse hídrico e com maior infestação, sendo possível inferir que essa diferença ocorreu devido ao consumo de $\mathrm{N}$ pelos insetos, pois embora $\mathrm{o}$ nitrogênio solúvel geralmente aumente durante a seca (KRAMER, 1983; MATTSON; HAACK, 1987), o efeito sobre o total de nitrogênio no tecido depende da intensidade e duração do estresse. Durante um estresse hídrico de suave para moderado, por exemplo, a concentração total de nitrogênio declina nas raízes e nos tecidos mais velhos, mas aumenta nos tecidos mais jovens, que são preferidos pelos afídeos.

Tabela 2. Teor de nitrogênio de mudas de Pinus taeda (acículas + caule), submetidas ou não a estresse hídrico, com e sem infestação por Cinara atlantica, em casa de vegetação, no período de 30/11/04 a 06/06/05, Colombo (PR).

Table 2. Nitrogen content in seedlings of Pinus taeda (needles + stem), on treatments with and without water stress and with and without Cinara atlantica infestation, in greenhouse, from 11/30/2004 to $06 / 06 / 2005$, Colombo (PR).

\begin{tabular}{lcc}
\hline Estresse hídrico & Inseto & Teor de nitrogênio (g/kg) \\
\hline Com & Sem & $17,0 \mathrm{a}$ \\
Com & Com & $15,1 \mathrm{ab}$ \\
Sem & Com & $14,7 \mathrm{~b}$ \\
Sem & Sem & $14,0 \mathrm{~b}$ \\
\hline
\end{tabular}

Ribeiro et al. (2003), em testes com adubação nitrogenada (sulfato de amônio) em mudas de Pinus taeda, em vasos de 3 litros infestados com pulgão e testemunha sem adubação, com um mês e 5 avaliações, verificaram ocorrência de pulgões (Cinara atlantica) superior e diferindo estatisticamente do número de pulgões na testemunha, bem como uma maior migração destes para as mudas que foram 
adubadas com sulfato de amônio. Esses dados corroboram esta pesquisa, que observou a preferência dos pulgões para as plantas submetidas ao estresse hídrico, que apresentaram maiores teores de nitrogênio.

Plantas de $P$. taeda de 18 meses, desenvolvidas em tubetes, em Três Barras (SC), apresentaram um teor médio de nitrogênio nas acículas entre 18 e $20 \mathrm{~g} \mathrm{~kg}^{-1}$ (S. Penteado, comunicação pessoal). Esse valor assemelha-se ao obtido por Reissmann; Wisniewski (2000), que verificaram que a concentração de nitrogênio nas acículas de $P$. taeda com 15 anos de idade, em solos com texturas diferentes, é em média de $18,38 \mathrm{~g} \mathrm{~kg}^{-1}$. O teor de nitrogênio obtido nesta pesquisa foi menor que os encontrados por esses autores, provavelmente porque foi avaliada toda a parte aérea da muda e não apenas as acículas, como no caso dos autores citados, sendo que a quantidade de nitrogênio é sempre menor no caule, fato que pode ter diminuído a quantidade média de $\mathrm{N}$ nas mudas avaliadas.

\section{Danos em mudas de $P$. taeda infestadas com $C$. atlantica sob condições de estresse hídrico em casa de vegetação}

As plantas sob estresse hídrico e sem infestação de $C$. atlantica apresentaram aumento significativo no crescimento em altura (Tabela 3) em relação aos outros tratamentos, porém essas mesmas plantas apresentaram redução no diâmetro (Tabela 3). Essa informação contradiz, em parte, o que afirma Kramer (1983), que uma das respostas mais sensíveis e imediatas da planta ao estresse hídrico em nível celular é uma redução no processo de crescimento, resultando em plantas mais baixas, afetando o desenvolvimento das folhas, brotos, órgãos reprodutivos e dos anéis de crescimento do xilema. Contudo, é importante considerar que o tempo de observação deve ser bem mais longo para se poder avaliar o resultado final em todos esses parâmetros.

Tabela 3. Incremento de altura e diâmetro $(\mathrm{cm})$ de mudas de Pinus taeda, com e sem estresse hídrico e com e sem infestação de Cinara atlantica, em casa de vegetação, no período de 30/11/04 a 06/06/05, Colombo (PR).

Table 3. Height increment and diameter $(\mathrm{cm})$ of Pinus taeda seedlings, in treatments with and without water stress and with and without Cinara atlantica infestation, in greenhouse, from 11/30/2004 to $05 / 06 / 2005$, Colombo (PR).

\begin{tabular}{lccc}
\hline Estresse hídrico & Inseto & Incremento em altura (cm) & Incremento em diâmetro (cm) \\
\hline Com & Sem & $20,4 \mathrm{a}$ & $2,8 \mathrm{c}$ \\
Com & Com & $11,2 \mathrm{~b}$ & $3,3 \mathrm{~b}$ \\
Sem & Sem & $10,3 \mathrm{~b}$ & $3,3 \mathrm{~b}$ \\
Sem & Com & $5,9 \mathrm{c}$ & $3,8 \mathrm{a}$ \\
\hline
\end{tabular}

*Médias seguidas por letras diferentes, nas colunas, diferem entre si pelo teste de Tukey a 1\%.

Para as plantas com estresse e com inseto e sem estresse e sem inseto, não houve diferença significativa para as variáveis de crescimento em altura e diâmetro. Porém, para as plantas com estresse e sem inseto, houve uma maior média em altura e menor média em diâmetro, diferindo significativamente das plantas sem estresse e com inseto, com menor média de altura e maior em diâmetro (Tabela 3).

Considerando-se o efeito da infestação de C. atlantica, Zaleski (2003) observou, em mudas de 150 dias de $P$. taeda em casa de vegetação, um aumento do crescimento diamétrico com infestações de $C$. atlantica em relação à testemunha, mas o contrário foi observado para o crescimento em altura. Os dados deste trabalho corroboram esses resultados, contudo os experimentos de Zaleski (2003) não foram realizados sob estresse hídrico, mas para avaliar o efeito das infestações de $C$. atlantica sobre esses parâmetros. De acordo com Schubert; Adams (1971) e Stoeckeler; Slabaugh (1967), citados por Zaleski (2003), o diâmetro do colo é reconhecido como o melhor indicador para o padrão de qualidade, sendo que mudas com maiores diâmetros, embora menores na altura, são consideradas mais resistentes que as estioladas.

Para a variável diâmetro, observou-se que plantas com insetos tiveram maior crescimento independentemente da situação de estresse (Tabela 3). O menor incremento em diâmetro ocorreu nas mudas submetidas ao estresse hídrico, mas sem inseto, exatamente o oposto do que aconteceu no incremento em altura das mudas, que foi o maior nesse tratamento.

Como se observa na figura 3, houve interferência no teor de nitrogênio das plantas atacadas por C. atlantica, uma vez que o índice de correlação foi menor e a inclinação da reta também foi menor do que a obtida para as mudas sem inseto. Pode-se inferir que houve consumo de nitrogênio por parte dos 
insetos, independentemente do estresse hídrico, comparando-se os valores de b (inclinação da reta), que foi de 0,07 para as mudas com inseto e de 0,34 para aquelas sem insetos. As mudas que mais cresceram apresentaram maiores teores de nitrogênio.

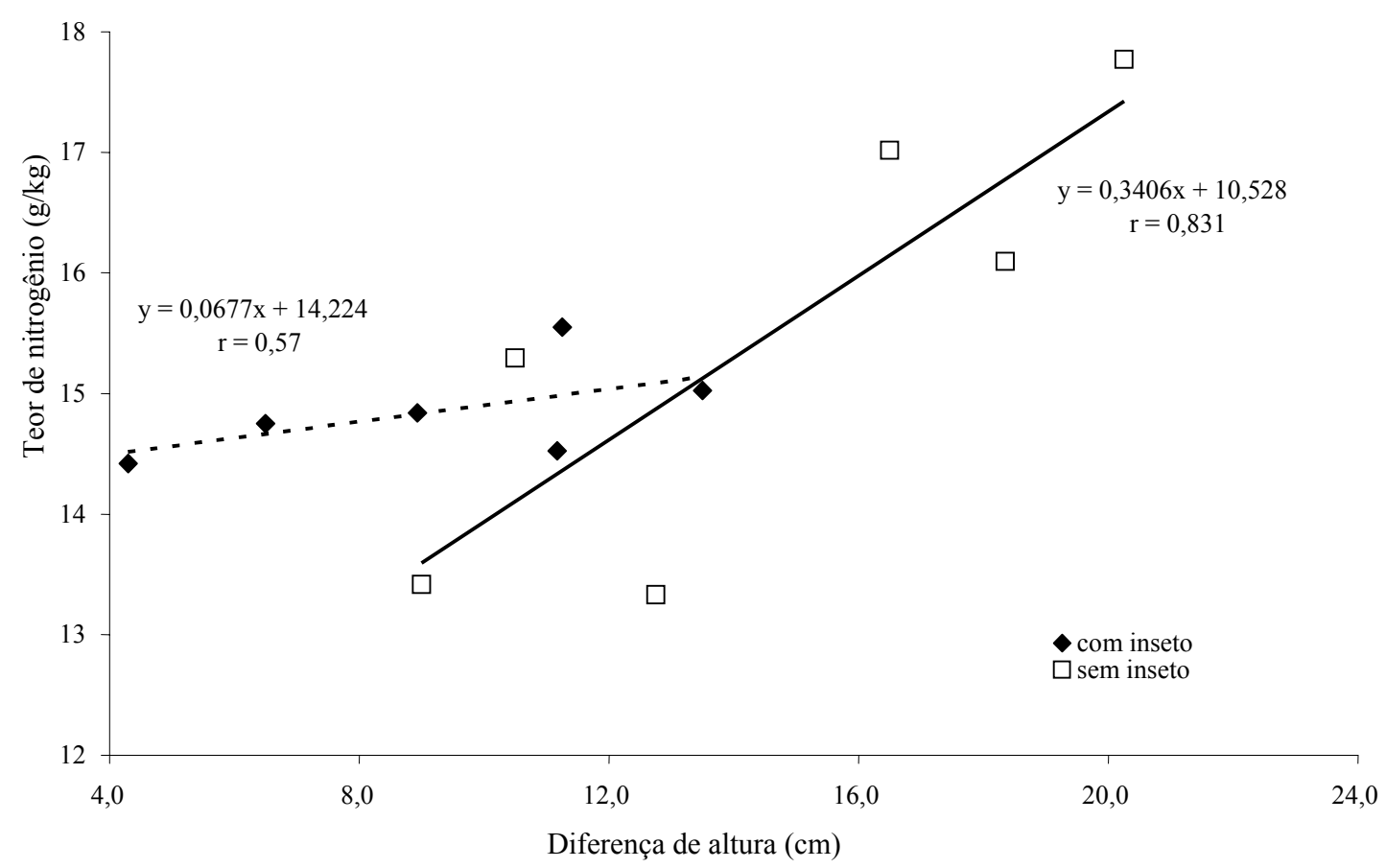

Figura 3. Regressão linear entre o teor de nitrogênio nas mudas (acículas + caule) de Pinus taeda e o crescimento em altura das mudas com e sem Cinara atlantica, em casa de vegetação, no período de 30/11/04 a 06/06/05, Colombo (PR).

Figure 3. Linear regression between nitrogen content in Pinus taeda seedlings (needles + stem) and seedlings increment in height with and without Cinara atlantica infestation, in greenhouse, from 11/30/2004 to 06/06/2005, Colombo (PR).

\section{CONCLUSÕES}

- $\mathrm{O}$ aumento do teor de nitrogênio nas mudas de P. taeda avaliadas correlaciona-se diretamente com o aumento no número de insetos.

- As mudas com estresse hídrico apresentam maiores teores de nitrogênio e maior incidência de pulgões.

- Em casa de vegetação, as plantas de $P$. taeda apresentam menor crescimento em altura na presença de insetos, com ou sem estresse hídrico.

- As mudas infestadas apresentam maior crescimento em diâmetro, independentemente do estresse hídrico, no tempo de observação e condições do estudo.

\section{REFERÊNCIAS}

FARIA, A. B. C. Monitoramento do pulgão-do-pinus e seu controle com aplicação de Imidacloprid. 60 f. Dissertação (Mestrado em Engenharia Florestal) - Setor de Ciências Agrárias, Universidade Federal do Paraná, Curitiba, 2004.

FOX, R. C.; GRIFFITH, K. H. Pine seedling growth loss caused by Cinara aphids in South Carolina. Journal of the Georgia Entomological Society, Tifton, v. 12. n. 1, p. 29-34, 1977. 
FURNISS, R. L.; CAROLIN, V. M. Western forest insects. Washington, DC: USDA Forest Service, 1977. 654 p. (Misc. Pub, n. 1339).

IEDE, E. T. Monitoramento das populações de Cinara spp. (Hemiptera: Aphididae: Lachninae), avaliação de danos e proposta para o seu manejo integrado em plantios de Pinus spp. (Pinaceae), no sul do Brasil. 171 f. Tese (Doutorado em Engenharia Florestal) - Setor de Ciências Agrárias, Universidade Federal do Paraná, Curitiba, 2003.

KFIR, R.; KIRSTEN, F.; VAN RENSBURG, N. J. Pauesia sp. (Hymenoptera: Aphidiidae), a parasite introduced into South Africa for biological control of the black pine aphid Cinara cronartii (Homoptera: Aphididae). Environmental Entomology, College Park, v. 14, p. 597-601, 1985.

KIDD, N.; JERVIS, M. Insect Natural Enemies. London: Chapman e Hall, 1995.

KIDD, N. A. C. The role of host plant in the population dynamics of the large pine aphid, Cinara pinea. Copenhagen, Oikos, Buenos Aires, v. 44, p 114-122, 1985.

KRAMER, P. J. Water Relations of Plants. Orlando, FL: Academic, 1983.

LARSSON, S. Seasonal changes in the within-crown distribution of the aphid Cinara pini on Scots pine. Copenhagen, Oikos, Buenos Aires, v. 45, p. 217-222, 1985.

LAZZARI, S. M. N.; ZONTA DE CARVALHO, R. C. Aphids (Homoptera: Aphididae: Lachninae: Cinarini) on Pinus spp. and Cupressus sp. in Southern Brazil. In: INTERNATIONAL CONGRESS OF ENTOMOLOGY, 21., 200, Foz do Iguaçu, PR. Anais... Londrina: Embrapa Soja, 2000. p. 493.

MATTSON, W. J.; HAACK, R. A. The role of drought stress in provoking outbreaks of phytophagous insects. In: BARBOSA, P.; SCHULTZ, J. (Eds.). Insect outbreaks: ecological and evolutionary perspectives. Orlando, FL: Academic, 1987.

MILLS, N. J. Biological control of forest aphid pests in Africa. Bulletin Entomological Research, London, v. 80, p. 31-36, 1990.

OTTATI, A. L. T. Aspectos bioecológicos do pulgão-gigante-do-pinus, Cinara atlantica (Wilson, 1919) (Hemiptera: Aphididae), em Pinus spp. (Pinaceae). 133 f. Tese (Doutorado) - Faculdade de Ciências Agronômicas, Universidade Estadual Paulista, Botucatu, 2004.

PANDOLFO, C.; BRAGA, H. J.; SILVA JR., V. P.; MASSIGNAN, A. M.; PEREIRA, E. S.; THOMÉ, V. M. R. Atlas climatológico digital do Estado de Santa Catarina. Florianópolis: Epagri, 2002. 1CDRom.

PRICE, W. P. The plant vigor hypothesis and herbivore attack. Copenhagen, Oikos, Buenos Aires, v. 62, p. 244-251, 1991.

RAVEN, H. P.; EVERT, F. R.; EICHHORN, S. E. Biologia vegetal. Rio de Janeiro: Guanabara Koogan, 1996. 587p.

RHOADES, D. F. Evolution of plant chemical defense against herbivores. In: ROSENTHAL, G. A.; JANZEN, D. H. (Eds). Herbivores: their interaction with secondary plant metabolites. New York: Academic, 1979. p. 3-54.

RIBEIRO, M. M.; FARIA, A. B. C.; SOUSA, N. J.; HARMUCH, D. A. Influência do nível de água no solo sobre a ocorrência de Pulgão-do-Pinus (Cinara sp). In: SIMPÓSIO SOBRE CINARA SPP. EM PINUS, Curitiba. Anais... Colombo: Emprapa Florestas, 2003.

RIBEIRO, M. M.; SOUSA, N. J.; REISSMANN, C. B.; DITTRICH, A. E.; CORRÊA, D. R.; FARIA, A. B. C. Avaliação da influência da adubação mitrogenada em Pinus taeda, sobre a ocorrência de Cinara sp (Hemiptera: Aphididae), o pulgão do Pinus. In: SIMPÓSIO SOBRE CINARA SPP. EM PINUS, Curitiba. Anais... Colombo: Emprapa Florestas, 2003.

SARRUGE, J. R.; HAAG, H. P. Análise química em plantas. Piracicaba: ESALQ, 1974. 56p. 
WEARING, C. H.; VAN EMDEN, H. F. Studies on the relations of insect and host Plant. I. - Effects of water stress in host plants in infestation by Aphis fabae Scop., Myzus persicae Sulz. and Brevicoryne brassicae L. Nature, London, v. 213, n. 5080, 1052p, 1967.

ZALESKI, S. R. M. Biologia, danos e determinação dos limites térmicos para o desenvolvimento de Cinara atlantica (Wilson, 1919) (Hemiptera: Aphididae) em Pinus taeda L. (Pinaceae). $70 \mathrm{f}$. Dissertação (Mestrado em Ciências Biológicas) - Setor de em Ciências Biológicas, Universidade Federal do Paraná, Curitiba, 2003. 